\title{
Women Veterans' Healthcare Delivery Preferences and Use by Military Service Era: Findings from the National Survey of Women Veterans
}

\author{
Donna L. Washington, MD, MPH' ${ }^{1,2,6}$, Bevanne Bean-Mayberry, $M D, M H S^{1,2}$, \\ Alison B. Hamilton, PhD, MPH ${ }^{1,3}$, Kristina M. Cordasco, MD, MPH, MSHS $1,2,4$, and Elizabeth $M$. \\ Yano, $\mathrm{PhD}, \mathrm{MSPH} \mathrm{H}^{1,5}$ \\ 1. VA Greater Los Angeles Health Services Research and Development (HSR\&D) Center of Excellence for the Study of Healthcare Provider \\ Behavior, Sepulveda, CA, USA; ${ }^{2}$, Department of Medicine, University of California Los Angeles (UCLA) David Geffen School of Medicine, Los \\ Angeles, CA, USA; ${ }^{3}$, Department of Psychiatry and Biobehavioral Sciences, University of California Los Angeles (UCLA) David Geffen School \\ of Medicine, Los Angeles, CA, USA; ${ }^{4}$, The RAND Corporation, Santa Monica, CA, USA; 5 Department of Health Policy and Management, UCLA \\ Fielding School of Public Health, Los Angeles, CA, USA; ${ }^{6}$, VA Greater Los Angeles Healthcare System, Los Angeles, CA, USA.
}

BACKGROUND: The number of women Veterans (WVs) utilizing the Veterans Health Administration (VA) has doubled over the past decade, heightening the importance of understanding their healthcare delivery preferences and utilization patterns. Other studies have identified healthcare issues and behaviors of WVs in specific military service eras (e.g., Vietnam), but delivery preferences and utilization have not been examined within and across eras on a population basis.

OBJECTIVE: To identify healthcare delivery preferences and healthcare use of WVs by military service era to inform program design and patient-centeredness.

DESIGN AND PARTICIPANTS: Cross-sectional 20082009 survey of a nationally representative sample of 3,611 WVs, weighted to the population.

MAIN MEASURES: Healthcare delivery preferences measured as importance of selected healthcare features; types of healthcare services and number of visits used; use of VA or non-VA; all by military service era.

KEY RESULTS: Military service era differences were present in types of healthcare used, with World War II and Korea era WVs using more specialty care, and Vietnam era-to-present WVs using more women's health and mental health care. Operations Enduring Freedom, Iraqi Freedom, New Dawn (OEF/OIF/OND) WVs made more healthcare visits than WVs of earlier military eras. The greatest healthcare delivery concerns were location convenience for Vietnam and earlier WVs, and cost for Gulf War 1 and OEF/OIF/OND WVs. Colocated gynecology with general healthcare was also rated important by a sizable proportion of WVs from all military service eras.

CONCLUSIONS: Our findings point to the importance of ensuring access to specialty services closer to home for WVs, which may require technology-supported care. Younger WVs' higher mental health care use reinforces the need for integration and coordination of primary care, reproductive health and mental health care.
KEY WORDS: women Veterans; VA healthcare; health services need; health services utilization; health care preferences.

J Gen Intern Med 28(Suppl 2):S571-6

DOI: $10.1007 /$ s11606-012-2323-y

(C) Society of General Internal Medicine 2013

\section{BACKGROUND}

The Veterans Health Administration (VA) - the largest integrated healthcare delivery system in the United States (U.S.) - is a forerunner of the Accountable Care Organization (ACO) model. ${ }^{1,2}$ ACOs, such as the VA, need to design services that map to the healthcare needs and delivery preferences of the different population groups they serve. ${ }^{3}$ Among the fastest growing segment of VA users are women Veterans (WVs), who account for more than one-half million enrollees and whose numbers have doubled in the past decade. ${ }^{4}$ Despite the growth in size of the WV population, women currently comprise less than $10 \%$ of U.S. Veterans, and therefore planning for the needs of this market segment requires separate and/or gender-stratified population-based assessments. ${ }^{5}$

Much prior research has documented gender differences in Veterans' characteristics, healthcare needs, healthcare delivery preferences, and receipt of evidence-based care. ${ }^{6-10}$ However, heterogeneity within the WV population (e.g., by military service era) was not addressed. ${ }^{11}$ A burgeoning literature on specific Veteran military service era groups (e.g., Vietnam) highlights salient health issues for these population segments, ${ }^{11-14}$ but delivery preferences and utilization have not been examined across eras on a population basis. Healthcare providers within and outside the VA would benefit from more knowledge distinguishing health and healthcare characteristics of different military groups. Understanding and accounting for era of military service among WVs may be important for considerations of how to tailor access and healthcare for women. 
The purpose of this paper is to examine healthcare delivery preferences and healthcare use of WVs by military service era, and identify implications for improving WVs' care.

\section{METHODS}

\section{Design and Sample}

Our methods have been described previously. ${ }^{15,16}$ Briefly, we conducted a cross-sectional national survey, enrolling a population-based, stratified random sample of WVs. Stratification was based on VA use/nonuse and military service period. ${ }^{16}$ Inclusion criteria were being a WV of the regular armed forces, or a member of the National Guard or Reserves who had been called to active duty. Exclusion criteria were current active military duty, VA employment, hospitalization or residence in a long-term care facility. Eighty-six percent of screened and eligible WVs consented to survey participation. ${ }^{16}$ We conducted computer-assisted telephone interviews over a 9-month period through May 2009. This study was approved by the Institutional Review Board of the VA Greater Los Angeles Healthcare System, and the survey was also approved by the U.S. Office of Management and Budget.

\section{Main Measures}

Survey items included previously validated measures and measures developed for the NSWV. Healthcare delivery preferences were assessed using items derived from an earlier regional study of WVs ambulatory care decision-making. ${ }^{17}$ These items were 4-point Likert scales on the importance of different healthcare delivery features in decision-making about healthcare. They were dichotomized to very important versus less than very important. Healthcare use in the prior 12 months was characterized by use of VA or non-VA healthcare, having a regular source and provider for healthcare (yes/no for each), type of healthcare services used (women's health [WH], other primary care, mental health $[\mathrm{MH}]$, specialty care), and number of healthcare visits. ${ }^{17-19} \mathrm{WH}$ services could include genderspecific preventive care (such as cervical cancer screening), gynecologic care, and obstetrical care.

Military service era was the main independent variable. We asked participants when they served in the military, allowing respondents to select multiple date ranges or service periods. Using established dates for U.S. military wartimes and peacetimes, ${ }^{20,21}$ we defined military service eras as starting with the beginning of a wartime period, and ending with the end of the subsequent peacetime. Given the small number of living WVs with service prior to the start of World War 2 (WWII), we combined pre-WWII veterans with the WWII group. For this analysis, veterans were assigned to the most recent military service era in which they served. This resulted in five military service eras:
WWII, Korea, Vietnam, Gulf War pre-9/11 (GW1), and Operations Enduring Freedom, Iraqi Freedom, and New Dawn (OEF/OIF/OND).

\section{Independent Variables}

Sociodemographic characteristics measured were: age, race/ ethnicity, marital status, education, employment, household income, insurance status, and military service-connected disability rating. Age was categorized into groups that correspond to reproductive years $(<45)$, middle age (45-64), and Medicare-eligibility $(\geq 65)$. Priority for VA enrollment is determined on the basis of military service-connected disability, income, recent military service, and other factors. Therefore, we used these variables to estimate whether or not respondents were in a high priority group for VA enrollment.

Health characteristics included self-reported overall health (fair-or-poor versus excellent/very good/good). We queried respondents about diagnosed physical health conditions using a list of medical conditions derived from prior Veteran surveys, then created summation measures for number of medical conditions. ${ }^{20}$ Similarly, we asked about diagnosed depression, post-traumatic stress disorder, or other diagnosed $\mathrm{MH}$ conditions, then created a summation measure for number of $\mathrm{MH}$ conditions.

\section{Statistical Analysis}

Our main comparisons were among the five groups of WVs as defined by their military service era. Characteristics of these groups were compared using chi-square tests for categorical variables and linear regression for continuous measures. To identify between-group differences in characteristics that had clinically relevant variations by military service era, we conducted four regression analyses per characteristic of interest, varying the military service era that was the reference group. This generated pairwise statistical comparisons among the five groups. See Table 1 for characteristics of WVs by military service era, and Table 2 for WV health care use and delivery preferences.

Sampling weights were developed from the inverse of the probabilities of inclusion in the sample. All analyses applied weights to account for disproportional allocation of the population by strata, so that resulting estimates are representative of the U.S. WV population. All analyses were conducted using STATA version 12.0. ${ }^{22}$

\section{RESULTS}

The NSWV enrolled 3,611 women Veterans, of whom 3,607 (99.9\%) provided data sufficient to categorize their military service era. The population distribution of WVs by military 
Table 1. Characteristics of U.S. Women Veterans by Military Service Era

\begin{tabular}{|c|c|c|c|c|c|}
\hline Characteristics & $\begin{array}{l}\text { WWII era } \\
(n=506)\end{array}$ & $\begin{array}{l}\text { Korea era } \\
(n=737)\end{array}$ & $\begin{array}{l}\text { Vietnam era } \\
(n=555)\end{array}$ & $\begin{array}{l}\text { Gulf War } 1 \text { era } \\
(n=780)\end{array}$ & $\begin{array}{l}\text { OEF/OIF/OND } \\
(n=1,029)\end{array}$ \\
\hline \multicolumn{6}{|l|}{ Sociodemographic characteristics } \\
\hline \multicolumn{6}{|l|}{ Age group in years $(\%)^{*}$} \\
\hline $18-44$ & 0.0 & 0.0 & 4.5 & 43.8 & 69.9 \\
\hline $45-64$ & 0.0 & 0.0 & 38.2 & 53.7 & 30.1 \\
\hline$\geq 65$ & 100.0 & 100.0 & 57.3 & 2.6 & 0.0 \\
\hline \multicolumn{6}{|l|}{ Race-ethnicity $(\%)^{*}$} \\
\hline Hispanic & 0.3 & 0.7 & 0.8 & 7.2 & 13.6 \\
\hline Non-Hispanic White & 93.6 & 87.8 & 86.1 & 69.2 & 59.2 \\
\hline Non-Hispanic Black & 0.2 & 2.2 & 7.8 & 14.7 & 20.9 \\
\hline \multirow{2}{*}{\multicolumn{6}{|c|}{ Marital status, current (\%) }} \\
\hline & & & & & \\
\hline Married or partnered & 19.6 & 31.7 & 47.6 & 72.3 & 57.8 \\
\hline Divorced & 5.9 & 20.0 & 11.9 & 13.9 & 17.8 \\
\hline Separated & 2.8 & 0.7 & 2.7 & 2.8 & 3.3 \\
\hline Widowed & 64.3 & 29.4 & 5.6 & 1.5 & 0.4 \\
\hline Never married & 7.4 & 18.2 & 32.2 & 9.5 & 20.8 \\
\hline College graduate $(\%)^{*}$ & 34.5 & 29.0 & 62.6 & 43.9 & 39.0 \\
\hline Employed (\%) & 0.4 & 8.0 & 28.0 & 65.9 & 67.2 \\
\hline Annual household income $<\$ 20,000(\%)^{*}$ & 36.9 & $\begin{array}{l}0.0 \\
26.8\end{array}$ & 8.8 & 6.3 & 10.2 \\
\hline \multicolumn{6}{|l|}{ Medical insurance $(\%)^{*}$} \\
\hline None & 8.9 & 9.7 & 10.9 & 11.2 & 22.6 \\
\hline Medicare $(+/-$ other insurance) & 85.3 & 85.1 & 59.2 & 3.6 & 0.3 \\
\hline Private or other only & 5.8 & 5.2 & 29.9 & 85.2 & 77.1 \\
\hline Has military service-connected disability $(\%)^{*}$ & 56.7 & 46.3 & 54.0 & 28.2 & 27.9 \\
\hline VA enrollment priority group high (\%) & 85.5 & 74.2 & 68.0 & 51.0 & 97.7 \\
\hline \multicolumn{6}{|l|}{ Health characteristics } \\
\hline Overall health status fair or poor $(\%)^{*}$ & 39.0 & 40.0 & 19.7 & 14.5 & 14.8 \\
\hline Number of diagnosed physical health conditions (mean $(\mathrm{SD}))^{*}$ & $3.8(2.2)$ & $3.5(3.0)$ & $2.5(1.3)$ & $1.2(0.8)$ & $0.7(2.3)$ \\
\hline One or more diagnosed physical health conditions (\%) & 99.5 & 98.0 & 89.3 & 65.1 & 44.4 \\
\hline Number of diagnosed mental health conditions (mean (SD)) ${ }^{*}$ & $0.1(0.5)$ & $0.4(1.0)$ & $0.4(0.5)$ & $0.4(0.4)$ & $0.5(1.8)$ \\
\hline One or more diagnosed mental health conditions $(\%)^{\dagger}$ & 10.9 & 33.8 & 30.1 & 32.3 & 33.6 \\
\hline
\end{tabular}

Column headers list unweighted sample size; table percentages and means are weighted population estimates for the U.S. woman veteran population

${ }^{*}<0.001,{ }^{\dagger} p=0.05$ for comparisons among groups

service era is shown in Table 3. GW1 WVs formed the largest military service era group, accounting for $51 \%$ of WVs.

\section{Characteristics by Military Service Era}

Characteristics of WVs by military service era are given in Table 1. There were differences by military service era on most characteristics assessed. The mean age in years was 87 for WWII, 77 for Korea, 64 for Vietnam, 46 for GW1, and 38 for $\mathrm{OEF} / \mathrm{OIF} / \mathrm{OND}$ era WVs. Seventy percent of $\mathrm{OEF} / \mathrm{OIF} /$ OND and $44 \%$ of GW1 WVs were in reproductive age groups. OEF/OIF/OND WVs were most likely and GW1 WVs were least likely to have high VA enrollment priority ( $p$ $<0.01$ for pairwise comparisons).

Overall health status and number of diagnosed physical health conditions varied by military service era, with WVs of more recent eras having better health on all physical health measures. By contrast, WWII era WVs had better health on all MH measures ( $p<0.01$ for pairwise comparisons).

\section{Health Care Delivery Preferences and Health Care Use}

Health care delivery preferences varied for some features of care, but not others (Table 2). Overall, features of care were rated as very important in healthcare decisionmaking by: $58.6 \%$ of WVs for cost of care; $58.5 \%$ for convenience of locations; $44.5 \%$ for co-located gynecologic with general healthcare; $35.3 \%$ for availability of after-hours care; and $21.8 \%$ for obtaining WH care from a WH clinic or doctor. WWII, Korea and Vietnam era WVs most often cited location convenience $(p=0.02)$, whereas GW1 and OEF/OIF/OND WVs most often cited cost of care $(p<0.01)$ as very important. Sizeable proportions of all groups rated co-located WH with general healthcare as important.

Though WVs from all military eras were all likely to have used healthcare (in any setting) in the prior 12 months, reliance on VA healthcare varied $(p<0.001)$. At $9 \%$ market penetration, GW1 WVs proportionately had the lowest VA reliance. However, given their numerically large size, they constitute $33 \%$ of WV VA users. Vietnam era women constitute $40 \%$ of VA users, OEF/OIF/OND $12 \%$, Korea $10 \%$, and WWII $5 \%$ (data not shown). With $35 \%$ using VA, OEF/OIF/OND WVs proportionately had the greatest $\mathrm{VA}$ reliance.

Types of healthcare services used and amount of healthcare use also varied (Table 2). OEF/OIF/OND and GW1 WVs were most likely to use WH and MH care. WWII and Korea era WVs were most likely to use specialty care. 
Table 2. Health Care Delivery Preferences and Health Care Use of U.S. Women Veterans by Military Service Era

\begin{tabular}{|c|c|c|c|c|c|}
\hline & $\begin{array}{l}\text { WWII } \\
\text { era } \\
(n=506)\end{array}$ & $\begin{array}{l}\text { Korea } \\
\text { era } \\
(n=737)\end{array}$ & $\begin{array}{l}\text { Vietnam } \\
\text { era } \\
(n=555)\end{array}$ & $\begin{array}{l}\text { Gulf War } 1 \\
\text { era } \\
(n=780)\end{array}$ & $\begin{array}{l}\text { OEF/OIF/ } \\
\text { OND } \\
(n=1,029)\end{array}$ \\
\hline \multicolumn{6}{|l|}{ Health care delivery preferences } \\
\hline $\begin{array}{l}\% \text { rating healthcare feature very important } \\
\text { Cost of care }\end{array}$ & 46.7 & 59.1 & 49.0 & 65.1 & 67.1 \\
\hline Convenience of the location ${ }^{\dagger}$ & 76.2 & 68.3 & 61.5 & 52.5 & 61.7 \\
\hline $\begin{array}{l}\text { Ability to obtain gynecology and general health care at same } \\
\text { place }\end{array}$ & 61.1 & 41.1 & 35.7 & 47.5 & 47.7 \\
\hline Ability to obtain an evening or weekend appointment & 31.2 & 41.4 & 33.1 & 35.1 & 48.1 \\
\hline $\begin{array}{l}\text { Ability to obtain women's health (WH) care from WH doctor } \\
\text { or clinic }\end{array}$ & 13.8 & 17.0 & 24.3 & 21.7 & 26.9 \\
\hline \multicolumn{6}{|l|}{ Health care use in prior 12 months } \\
\hline Any health care use $(\%)$ & 91.5 & 95.5 & 93.7 & 87.5 & 92.4 \\
\hline Any VA health care use $(\%)^{*}$ & 10.3 & 20.1 & 19.0 & 9.0 & 35.0 \\
\hline No regular source of health care $(\%)^{\star}$ & 6.2 & 2.1 & 1.9 & 9.3 & 21.4 \\
\hline No regular provider (e.g., PCP) $(\%)^{\ddagger}$ & 14.2 & 7.3 & 15.2 & 33.6 & 37.5 \\
\hline $\begin{array}{l}\text { Types of healthcare services used in any healthcare setting } \\
\text { Women's health (WH) care }(\%)^{\ddagger}\end{array}$ & 30.1 & 45.9 & 55.6 & 71.7 & 71.6 \\
\hline Primary care other than WH (\%) & 79.2 & 83.0 & 87.3 & 84.9 & 73.7 \\
\hline Mental health care $(\%)^{*}$ & 3.6 & 6.1 & 11.1 & 16.2 & 22.3 \\
\hline Specialty care $(\%)^{\ddagger}$ & 71.7 & 69.6 & 62.6 & 47.3 & 43.7 \\
\hline $\begin{array}{l}\text { Number of health care visits in any healthcare setting (mean } \\
(\text { SD) })^{\S}\end{array}$ & $6.1(12.9)$ & $8.6(20.8)$ & $8.1(9.1)$ & $5.9(9.2)$ & $10.2(41.8)$ \\
\hline
\end{tabular}

Column headers list unweighted sample size; table percentages and means are weighted population estimates for the U.S. woman veteran population

$\stackrel{*}{p}<0.01,{ }^{\dagger} p=0.02,{ }_{p}^{*}<0.001,{ }_{p}=0.002$ for comparisons among groups

Vietnam era WVs were intermediate between WVs of earlier and later eras in use of these services. OEF/OIF/ OND WVs had more healthcare visits than WVs of earlier military eras.

\section{DISCUSSION}

We found that the U.S. WV population is comprised of distinct military service era groups in different life stages,

Table 3. Population Estimates of U.S. Women Veterans by Military Service Era

\begin{tabular}{|c|c|c|c|c|c|c|}
\hline & \multicolumn{6}{|l|}{ Ending era } \\
\hline & WWII & Korea & Vietnam & Gulf War 1 & OEF/OIF/OND & Total \\
\hline $\begin{array}{l}\text { Wartime } \\
\text { Peacetime }\end{array}$ & $\begin{array}{l}9 / 16 / 40-7 / 25 / 47 \\
7 / 26 / 47-6 / 26 / 50\end{array}$ & $\begin{array}{l}6 / 27 / 50-1 / 31 / 55 \\
2 / 01 / 55-8 / 04 / 64\end{array}$ & $\begin{array}{l}8 / 05 / 64-5 / 07 / 75 \\
5 / 08 / 75-8 / 01 / 90\end{array}$ & $\begin{array}{l}8 / 02 / 90-2 / 28 / 91 \\
3 / 01 / 91-9 / 10 / 01^{\dagger}\end{array}$ & 9/11/01- & \\
\hline \multicolumn{7}{|l|}{ Starting era } \\
\hline WWII era ${ }^{*}$ & $7.2 \%$ & $1.6 \%$ & $1.0 \%$ & & & $9.7 \%$ \\
\hline Korea era & & $5.4 \%$ & $12.2 \%$ & $0.7 \%$ & & $18.3 \%$ \\
\hline Vietnam era & & & $16.6 \%$ & $34.9 \%$ & $1.9 \%$ & $53.3 \%$ \\
\hline Gulf war 1 era & & & & $15.8 \%$ & $2.0 \%$ & $17.8 \%$ \\
\hline OEF/OIF/OND & & & & & $0.9 \%$ & $0.9 \%$ \\
\hline Total & $7.2 \%$ & $7.0 \%$ & $29.7 \%$ & $51.4 \%$ & $4.8 \%$ & $100.0 \%$ \\
\hline
\end{tabular}


and varying in their healthcare needs, delivery preferences, and use. Types of healthcare services used reflect both agerelated and military service era-related associations.

Despite their younger age, OEF/OIF/OND WVs had the greatest average use of healthcare. OEF/OIF/OND and GW1 WVs had the highest prevalence of WH services use, which may be related to both reproductive health and deployment-related effects. ${ }^{23} \mathrm{MH}$ service use was also greatest for the most recent eras of Veterans, consistent with previously documented needs. ${ }^{24,25}$ Compared with other groups, OEF/OIF/OND WVs had the greatest VA reliance. This higher utilization of VA services by this group of newer Veterans has significant implications for resource needs. As this population grows, VA must continue to monitor availability, quality, and delivery arrangements for comprehensive WH care that includes reproductive health services and $\mathrm{MH}$ care.

Healthcare cost was an important factor for OEF/OIF/ OND and GW1 WVs. These two groups were also more likely to lack a regular healthcare provider for care. Having a regular healthcare provider is an important predictor of receiving preventive care services. ${ }^{26}$ Further, care continuity is important for achieving optimal chronic disease management. ${ }^{27,28}$ Therefore, if U.S. healthcare reform and VA outreach efforts are successful in improving access to a regular healthcare provider for these groups, health outcomes for these WVs may be improved. ${ }^{1,16}$

Many Vietnam, Korea, and WWII WVs have multiple medical conditions. Concordantly, they had the highest prevalence of specialty care use. Convenience of healthcare location being an important factor for these groups gives support for VA's specialty care transformational initiatives to improve the convenience of care and reduce patient travel costs through the provision of virtual healthcare and consultative support. Further, with a sizable proportion of Vietnam and Korea WVs having MH conditions, geriatric and extended care services need to incorporate or be coordinated with MH care.

WH clinics and co-location of gynecologic with general healthcare were important healthcare features for a sizable proportion of WVs. These healthcare features have been incorporated as WH care delivery models within VA. Efforts are underway to assure that such comprehensive care is available in VA community-based outpatient clinics, which may be more conveniently located for WVs than VA hospitals. $^{29}$

Healthcare delivery for WVs should account for their military service era-related needs, preferences, and use. Since many WVs obtain healthcare outside the VA, health plans and providers in all settings should be informed about WVs' healthcare needs and delivery preferences. Within the VA, findings from this national, population-based study suggest that the next steps in VA's research and policy agendas should be to accelerate implementation of comprehensive WH care, accounting for military service era variations.

\section{Acknowledgements:}

Contributors: The authors gratefully acknowledge Mark Canning for project management, Julia Yosef, MA for assistance with survey fieldwork, Su Sun, MPH for assistance with data management, and Michael Mitchell, PhD, for statistical assistance.

Funders: This study was funded by the Department of Veterans Affairs (VA) Women's Health Services in the Office of Patient Care Services, and the VA Health Services Research and Development (HSR\&D) Service (\#SDR-08-270). Dr. Yano is supported by a VA HSR\&D Research Career Scientist award (\#RCS-05-195). Dr. BeanMayberry was supported by a VA HSR\&D Research Career Development Transition award (\#RCD 02-039) during this study. The views expressed within are solely those of the authors, and do not necessarily represent the views of the Department of Veterans Affairs or the United States government.

Conflict of Interest: All authors are employed by the Department of Veterans Affairs. Drs. Washington, Cordasco, and Yano receive research funding from the VA Health Services Research and Development Service and from the VA Office of Patient Care Services.

Corresponding Author: Donna L. Washington, MD, MPH; , VA Greater Los Angeles Healthcare System, 11301 Wilshire Blvd., $111 G$, Los Angeles, CA 90073, USA (e-mail: Donna. washington@va.gov).

\section{REFERENCES}

1. $111^{\text {th }}$ United States Congress. Patient Protection and Affordable Care Act (Public Law 111-148), and Health Care and Education Reconciliation Act of 2010 (Public Law 111-152). Available at: http://www.gpo.gov/ fdsys/browse/collection.action?collectionCode=PLAW. Accessed December 4, 2012.

2. Jha AK, Perlin JB, Kizer KW, Dudley RA. Effect of transformation of the Veterans health care system on quality of care. N Engl J Med. 2003;348:2218-27.

3. Dept of Veterans Affairs, Office of Policy and Planning. About OPP. Available at: http://www.va.gov/op3/About_OPP.asp. Accessed December 4, 2012.

4. Frayne SM, Phibbs CS, Friedman SA, Berg E, Ananth L, Iqbal S, et al. Sourcebook: Women Veterans in the Veterans Health Administration. Volume 1. Sociodemographic Characteristics and Use of VHA Care. Women's Health Evaluation Initiative, Women Veterans Health Strategic Health Care Group, Veterans Health Administration, Department of Veterans Affairs, Washington DC. December 2010.

5. Washington DL. Challenges to studying and delivering care to special populations-the example of women Veterans. J Rehabil Res Dev. 2004;41(2):ix-xi.

6. Teh CF, Kilbourne AM, McCarthy JF, Welsh D, Blow FC. Gender differences in health-related quality of life for veterans with serious mental illness. Psychiatr Serv. 2008;59(6):663-9.

7. Haskell SG, Mattocks K, Goulet JL, Krebs EE, Skanderson M, Leslie D, et al. The burden of illness in the first year home: do male and female VA users differ in health conditions and healthcare utilization. Women's Health Issues. 2011;21(1):92-7.

8. Kaur S, Stechuchak KM, Coffman CJ, Allen KD, Bastian LA. Gender differences in health care utilization among Veterans with chronic pain. J Gen Intern Med. 2007;22(2):228-33.

9. Tseng CL, Sambamoorthi U, Rajan M, Tiwari A, Frayne S, Findley P, et al. Are there gender differences in diabetes care among elderly Medicare enrolled Veterans? J Gen Intern Med. 2006;21(Suppl 3):S47-53. 
10. Sambamoorthi U, Mitra S, Findley PA, Pogach LM. Decomposing gender differences in low-density lipoprotein cholesterol among veterans with or at risk for cardiovascular illness. Women's Health Issues. 2012;22(2):e201-8.

11. Bean-Mayberry B, Huang C, Batuman F, Goldzweig C, Washington DL, Yano EM, et al. Systematic Review of Women Veterans Health Research 2004-2008 [Internet]. VA-ESP Project \#05-226; 2010 Oct. Available at: http://www.hsrd.research.va.gov/publications/esp/women.cfm. Accessed December 4, 2012.

12. Thomas TL, Kang HK, Dalager NA. Mortality among women Vietnam veterans, 1973-1987. Am J Epidemiol. 1991;134(9):973-80.

13. Bell EA, Roth MA, Weed G. Wartime stressors and health outcomes: women in the Persian Gulf War. J Psychosoc Nurs Ment Health Serv. 1998;36:19-25.

14. Street AE, Vogt D, Dutra L. A new generation of women veterans: stressors faced by women deployed to Iraq and Afghanistan. Clin Psychol Rev. 2009;29(8):685-94.

15. Washington DL, Sun S, Canning M. Creating a sampling frame for population-based veteran research: coverage and overlap of VA and nonVA databases. J Rehabil Res Dev. 2010;47(8):763-71.

16. Washington DL, Bean-Mayberry B, Riopelle D, Yano EM. Access to care for women veterans: delayed healthcare and unmet need. J Gen Intern Med. 2011;26(Suppl 2):655-61.

17. Washington DL, Yano EM, Simon B, Sun S. To use or not to use-what influences why women veterans choose VA healthcare? J Gen Intern Med. 2006;21(Suppl 3):S11-8.

18. Andersen R. Revisiting the behavioral model and access to medical care: does it matter? J Health Soc Behav. 1995;36:1-10.

19. Aday LA, Awe WC. Health services utilization models. In: Gochman DS, ed. Handbook of Health Behavior Research I: Personal and Social Determinants. New York: Plenum Publishing Corporation; 1995.

20. National Center for Veterans Analysis and Statistics. National Survey of Veterans Methodology and Appendixes. Appendix C. NSV 2001
Extended Interview Questionnaire and CATI specifications. Available at: http://www.va.gov/VETDATA/SurveysAndStudies/Methology_and_ Appendixes.asp. Accessed December 4, 2012.

21. National Center for Veterans Analysis and Statistics. Gulf War Era Veterans Report: Pre-9/11. Available at: http://www.va.gov/vetdata/docs/ SpecialReports/GW_Pre911_report.pdf. Accessed December 4, 2012.

22. StataCorp. Stata: Release 12. Statistical Software. College Station, TX: StataCorp LP; 2011

23. Batuman F, Bean-Mayberry B, Goldzweig CL, Huang C, Miake-Lye IM, Washington DL, et al. Health effects of military service on Women Veterans [Internet]. VA-ESP Project \#05-226; 2011. Available at: http:// www.hsrd.research.va.gov/publications/esp/women-vets.cfm. Accessed December 4, 2012.

24. Cohen BE, Maguen S, Bertenthal D, Shi Y, Jacoby V, Seal KH. Reproductive and other health outcomes in Iraq and Afghanistan women veterans using VA health care: association with mental health diagnoses. Women's Health Issues. 2012;22(5):e461-71.

25. Bean-Mayberry B, Yano EM, Washington DL, Goldzweig C, Batuman F, Huang C, et al. Systematic review of women veterans' health: update on successes and gaps. Women's Health Issues. 2011;21(4 Suppl):S8497.

26. Ward RA. Age and patterns of HMO satisfaction. J Aging Health. 1990;2 (2):242-60.

27. Parchman ML, Pugh JA, Noel PH, Larme AC. Continuity of care, selfmanagement behaviors, and glucose control in patients with type 2 diabetes. Med Care. 2002;40:137-44.

28. Cree M, Bell NR, Johnson D, Carriere KC. Increased continuity of care associated with decreased hospital care and emergency department visits for patients with asthma. Dis Manag. 2006;9(1):63-71.

29. Chapko MK, Borowsky SJ, Fortney JC, Hedeen AN, Hoegle M, Maciejewski ML, et al. Evaluation of the Department of Veterans Affairs community-based outpatient clinics. Med Care. 2002;40 (7):555-60. 